\title{
The prognostic impact of MGMT expression on low-grade gangliogliomas: a clinicopathological and immunohistochemical study
}

\author{
I-Wei Chang ${ }^{1,2}$, Chao-Tien Hsu ${ }^{2,3}$, Jui-Wei Lin ${ }^{4}$, Chih-Hsin Hung ${ }^{1}$ \\ ${ }^{1}$ Institute of Biotechnology and Chemical Engineering, I-Shou University, Kaohsiung, ${ }^{2}$ Department of Pathology, E-DA Hospital, I-Shou \\ University, Kaohsiung, ${ }^{3}$ School of Medicine, I-Shou University, Kaohsiung, ${ }^{4}$ Department of Pathology, Kaohsiung Chang Gung Memorial \\ Hospital and Chang Gung University College of Medicine, Kaohsiung, Taiwan
}

\begin{abstract}
Ganglioglioma $(G G)$ is an uncommon brain parenchymal neoplasm. Although most cases have indolent clinical behaviour, a subgroup of GGs does recur, especially in patients with unresectable disease. $O^{6}$-methylguanine DNA methyltransferase (MGMT) is a DNA repair protein that removes mutagenic and cytotoxic adducts from $O^{6}$-guanine in DNA. Lack of MGMT protein expression immunohistochemically is related to drug responses in patients with malignant glioma treated with alkylating agents. Furthermore, MGMT promoter methylation has also been investigated as an independent favourable prognostic factor for glioblastoma. The primary management is surgical resection for GGs and gross total resection is recommended. Despite infrequent use of chemotherapy for low-grade GGs, it was still introduced to a subset of patients, especially those who had unresectable disease. We assessed clinicopathological features of nine cases of low-grade GG to further elucidate the relationship between the status of the MGMT protein expression and the prognosis. This series included four men and five women with a mean age of 21.6 years at the first surgery. The mean postoperative follow-up period was 6 years. Only two patients had recurrent disease after 1.7 and 3.2 years of the first surgery. Immunohistochemically, $11.1 \%$ exhibited 3+ nuclear staining for MGMT protein, $11.1 \%$ exhibited $2+$ staining, 33.3\% exhibited $1+$ staining, and $44.4 \%$ exhibited 0 staining. Tumours with more intensive MGMT protein expression (2+ 3+ immunostaining) tended to recur more frequently $(p<0.05)$, corresponding to the worse prognostic predictive value of intensive MGMT staining.
\end{abstract}

Key words: ganglioglioma, low-grade, MGMT, O6-methylguanine-DNA methyltransferase, WHO grade I.

\section{Introduction}

Gangliogliomas (GGs) are benign tumours that were first identified by Perkins in 1926 as a distinct type of intracranial neoplasm [20]. They are typically well-differentiated, slowly growing neuroepithelial tumours, composed of neoplastic, mature ganglion cells, in combination with neoplastic glial cells. Both the glial and neuronal cells are believed to evolve from a common precursor cell in a hamartomatous glioneuronal lesion that subsequently differentiates to form neoplastic glial and neuronal elements $[3,29]$. GGs represent only $0.4 \%$ of all central nervous system (CNS) neoplasms and $1.3 \%$ of all brain tumours 
[11]. While rare, they are the most common of the glioneuronal neoplasms that arise within the central neuraxis. Although any site within the neuraxis may be affected, most tumours develop in the temporal lobe (approximately 70\%) [5,17,28]. Gangliogliomas represent the number one tumour entity in young patients suffering from chronic, intractable focal epilepsy $[4,16,18]$. The mean/median age at diagnosis ranges from 8.5 to 25 years $[9,12,21,28]$. The vast majority of GGs have excellent long-term prognosis following adequate surgical resection [12,17]. Local recurrence may occur especially in patients who have undergone subtotal resection $[6,17]$. The latest World Health Organization (WHO) classification of tumours of the central nerve system (2007) divides GGs into grade I and III, corresponding to ganglioglioma and anaplastic ganglioglioma [14]. Malignant transformation of low-grade GGs is exceptional and generally restricted to the glial component $[9,17,21,28]$. The primary management is surgical resection for all grades of gangliogliomas and gross total resection is recommended if technically feasible. Adjuvant radiation therapy may delay the time to progression for unresectable tumours [6]. However, the use of chemotherapy is still controversial for low-grade GGs $[6,17,25]$ but is warranted for anaplastic counterparts. The chemotherapeutic regimens introduced for anaplastic GGs are similar to those for high-grade gliomas, i.e. temozolamide, nitrosoureas, procarbazine, thiotepa and platinum-based drugs.

$\mathrm{O}^{6}$-methylguanine DNA methyltransferase (MGMT) is a DNA repair protein that removes mutagenic and cytotoxic adducts from $\mathrm{O}^{6}$-guanine in DNA. Methylation of discrete regions of the $\mathrm{CpG}$ island of the MGMT gene is associated with the silencing of the gene $[23,27]$. The DNA-repair enzyme MGMT is also a key factor in resistance to alkylating agents, because the transfer of alkyl groups to MGMT prevents the formation of lethal cross-links in DNA $[15,19]$. Furthermore, MGMT promoter methylation has been investigated as an independent favourable prognostic factor for glioblastoma [8]. To investigate the expression status of MGMT protein, and the possible prognostic impact on low-grade GGs, we conducted the current study.

\section{Material and methods}

This retrospective clinicopathological and immunohistochemical study was approved by the institutional review board of our institutes. Between
1998 and 2012, there were 11 cases of ganglioglioma diagnosed at the Departments of Pathology of Kaohsiung Chang Gung Memorial Hospital and E-DA Hospital. One case of primary anaplastic ganglioglioma was excluded. Another case was also excluded due to lack of residual tissue for further study. As a result, nine cases of ganglioglioma were enrolled in the present study. Clinical data, which included age, sex, location of involvement, treatment and clinical follow-up, were obtained from the medical records. Routine hematoxylin-eosin-stained sections were generated from formalin-fixed, paraffin-embedded tissue, which was cut to $3 \mu \mathrm{m}$-thick. Tumours were graded based on the 2007 revision of the new World Health Organization (WHO) classification of tumours of the central nerve system [14].

Immunohistochemical stains were performed using standard reagents and techniques on an i6000 Automated Staining System (BioGenex, San Ramon, CA). The following antibodies were used for immunohistochemistry: glial fibrillary acidic protein (GFAP) (clone ZCG29, Invitrogen, Carlsbad, CA, USA; steam in citrate buffer, $1: 150$ ), S-100 (polyclonal, Dako, Carpinteria, CA, USA; 1 : 1000), CD34 (clone QBEnd/10, NeoMarkers, Fremont, CA, USA; steam in citrate buffer, 1 : 400), MIB-1 antigen (clone MIB-1, Dako; steam in citrate buffer, $1: 100$ ), synaptophysin (clone 27G12, Novocastra, Newcastle upon Tyne, UK; steam in citrate buffer, 1 : 200), chromogranin A (clone 5H7, Novocastra; steam in citrate buffer, $1: 100$ ), neurofilament (clone NE14, BioGenex; steam in citrate buffer, $1: 150$ ), neuron-specific enolase (NSE) (clone BB5/ NC/VI-H14, Dako; steam in citrate buffer, $1: 100)$ and $\mathrm{O}^{6}$-methylguanine-DNA methyltransferase (MGMT) (clone MT 3.1, NeoMarkers; steam in citrate buffer, $1: 40$ ). Inactivation of endogenous peroxidase activity was obtained by incubating sections in $3 \% \mathrm{H}_{2} \mathrm{O}_{2}$ for 15 min. Localization of bound antibodies was performed with a non-biotin polymeric technology (Super Sensitive ${ }^{\top M}$ Polymer-HRP Detection System; BioGenex). Immunoreactions were visualized using 3,30-diaminobenzidine tetrahydrochloride $\left(Z_{Y M E D}{ }^{\circledR}\right.$; Invitrogen, Carlsbad, CA, USA). Appropriate positive controls for each antibody were run in parallel. For evaluation of MGMT, the immunostained slides were assessed for both extent and intensity of staining. The percentage of tumour with positive staining was estimated first. Next, the intensity of staining was semiquantitatively scored from 0 to $3+$. The rough percentage of tumour with positive staining and the 
Table I. Summary of histopathological and immunohistochemical findings

\begin{tabular}{lcccccc}
\hline Case no. & WHO grade & Necrosis & Haemorrhage & $\begin{array}{c}\text { Mitotic count } \\
(/ 10 \mathrm{HPF})\end{array}$ & Calcification & MGMT \\
\hline 1 & I & No & No & 0 & No & $75 \%, 1+$ \\
\hline 2 & 1 & No & No & 0 & No & 0 \\
\hline 3 & I & No & No & 0 & Yes & 0 \\
\hline 4 & 1 & No & No & 0 & Yes & 0 \\
\hline 5 & 1 & No & No & 0 & Yes & $20 \%, 1+$ \\
\hline 7 & 1 & No & No & 0 & Yes & $80 \%, 1+$ \\
\hline 8 & 1 & No & No & 0 & Yes & 0 \\
\hline 9 & 1 & No & No & 0 & No & $75 \%, 2+$ \\
\hline
\end{tabular}

HPF- high-power field, MGMT-O - ${ }^{6}$-methylguanine-DNA methyltransferase, WHO - World Health Organization

The extent of immunohistochemical staining is expressed semiquantitatively: the percentage of the tumour cells with observable staining, followed by the intensity of staining $(0,1+, 2+, 3+)$.

semiquantitative measure of staining intensity were then tabulated for each specimen (Table I).

Progression-free survival (PFS) interval was defined as the period from first diagnosis to first local recurrence. The statistical analysis was performed using SPSS for Windows 11.0 software (SPSS, Chicago, IL, USA). Progression-free survival was estimated by the Kaplan-Meier analysis and compared using the log-rank test. A p-value of 0.05 or less was considered statistically significant.

\section{Results}

\section{Clinical course}

The essential clinical information of all 9 cases is summarized in Table II. This series included 4 men and 5 women with a mean age of 21.6 years at first surgery. The most prevalent site was temporal lobes, accounting for $44.4 \%$ (4/9) of all cases. The other sites of the brain parenchymal tumours included occipital lobes $(2 / 9,22.2 \%)$, frontotemporal lobe $(1 / 9,11.1 \%)$, cerebellum $(1 / 9,11.1 \%)$, and spinal cord $(1 / 9,11.1 \%)$. The tumours ranged from 1.5 to $6.0 \mathrm{~cm}$ in the greatest diameter, and the mean diameter was $3.2 \mathrm{~cm}$. The most common initial symptom was seizure $(6 / 9,66.7 \%)$. Other manifestation included headache, nausea, vomiting, and pain and numbness of right lower extremities.

Clinical follow-up after diagnosis was available for all patients with a mean follow-up period of 6 years (range: 1.6 to 12.3 years). Seven of nine patients (77.8\%) had gross total resection at the first surgery and two (22.2\%) had subtotal resection. Only one patient who had an unresectable tumour (case 9) received postoperative radiotherapy and chemotherapy of temozolomide. Only two patients (cases 8 and 9) had recurrent disease after 1.7 and 3.2 years of the first surgery. One patient (case 8) underwent radiosurgery for recurrent disease. Temozolomide was administered to one patient (case 9) for the recurrent tumour at first. Because of ineffectiveness of chemotherapy, subtotal resection was finally performed for the recurrent disease. The mean progression-free survival was 4.9 years. All patients were alive at the last clinical follow-up.

\section{Light microscopy and immunohistochemistry}

In total, we obtained specimens from nine primary tumours. The histological and immunohistochemical characteristics are listed in Table I. All tumours belonged to WHO grade I. Microscopically, all tumours were composed of both neuronal and glial cell elements (Figs. $1 \mathrm{~A}$ and $2 \mathrm{~B}$ ). The dysmorphic neuronal cells exhibited cytomegaly, focal binucleation and perimembranous aggregated Nissl substance, and were distributed unevenly in either clusters or scattered individually within the tumour (Figs. $1 \mathrm{~A}$ and $2 \mathrm{~B})$. The glial component was composed of neoplastic astrocytes with small bland-looking nuclei in a patternless fibrillary matrix (Fig. 1A). Calcifications were observed in six of nine tumours (66.7\%) (Fig. 2A). Necrosis and haemorrhage were not found.

Immunohistochemically, the glial cell components were immunoreactive to GFAP (Fig. 2C) and S-100 pro- 
Table II. Summary of clinical data

\begin{tabular}{|c|c|c|c|c|c|c|c|c|c|}
\hline $\begin{array}{l}\text { Case } \\
\text { no. }\end{array}$ & $\begin{array}{c}\text { Age } \\
\text { (years)/ } \\
\text { sex }\end{array}$ & $\begin{array}{c}\text { Initial } \\
\text { symptoms }\end{array}$ & $\begin{array}{c}\text { Tumour size }(\mathrm{cm}) / \\
\text { location }\end{array}$ & $\begin{array}{l}\text { Extent of } \\
\text { surgery }\end{array}$ & RT & RS & $\mathrm{CT}$ & $\begin{array}{l}\text { Local } \\
\text { recurrence and } \\
\text { time (years) }\end{array}$ & Clinical outcome \\
\hline 1 & $27 / M$ & Seizure & 1.5/left occipital & GTR & No & No & No & No & NED, 3.3 years $^{c}$ \\
\hline 2 & $23 / M$ & Seizure & NK/right temporal & GTR & No & No & No & No & NED, 7.7 years $^{c}$ \\
\hline 3 & $3 / M$ & Seizure & 1.5/left temporal & GTR & No & No & No & No & NED, 3.4 years $^{c}$ \\
\hline 4 & $6 / F$ & Seizure & 3.0/left temporal & GTR & No & No & No & No & NED, 12.3 years $^{c}$ \\
\hline 5 & $39 / F$ & $\begin{array}{l}\text { Incidental } \\
\text { finding }\end{array}$ & 5.5/left occipital & GTR & No & No & No & No & NED, 1.6 years $^{c}$ \\
\hline 6 & $6 / M$ & $\begin{array}{c}\text { Head- } \\
\text { ache, N/V, } \\
\text { unsteady } \\
\text { gait }\end{array}$ & $\begin{array}{l}\text { NK/right cerebel- } \\
\text { lum }\end{array}$ & GTR & No & No & No & No & NED, 3.3 years $^{c}$ \\
\hline 7 & $19 / F$ & $\begin{array}{l}\text { Pain and } \\
\text { numbness } \\
\text { of right } \\
\text { lower } \\
\text { extremities }\end{array}$ & $\begin{array}{c}\text { 6.0/spinal cord, } \\
\text { C6-T5 }\end{array}$ & STR & No & No & No & No & AWT, 8.1 years $^{c}$ \\
\hline 8 & $34 / F$ & $\begin{array}{l}\text { Headache, } \\
\text { seizure }\end{array}$ & 2.5/left temporal & GTR & No & Yes $^{b}$ & No & Yes (1.7) & NED, 10.6 years $^{c}$ \\
\hline 9 & $37 / F$ & Seizure & $\begin{array}{l}\text { 2.1/left frontotem- } \\
\text { poral }\end{array}$ & STR & Yes $^{a}$ & No & $Y_{e s}^{a, b}$ & Yes (3.2) & $\mathrm{AWT}^{\mathrm{d}}, 3.8$ years $^{\mathrm{c}}$ \\
\hline
\end{tabular}

AWT - alive with tumour, C - cervical spine, CT - chemotherapy (temozolomide), F-female, GTR - Gross total resection, $M$ - male, NED - no evidence of disease, NK - not known, N/V - nausea and vomiting, RS - stereotactic radiosurgery, RT-external beam radiotherapy, STR - subtotal resection, $T$ - thoracic spine

a For primary tumour, ${ }^{b}$ for recurrent tumour, ${ }^{c}$ time from first surgery at our hospital to last visit.

${ }^{d}$ The patient underwent subtotal resection for recurrent tumour after ineffective treatment of temozolomide.

teins, while the neuronal cell components showed positive immunostaining for neurofilament, synaptophysin (Fig. 2D), NSE (Fig. 2E) and variable chromogranin A. One of the nine tumours (11.1\%) exhibited $3+$ nuclear staining for MGMT protein (Fig. 2F), one (11.1\%) exhibited 2+ staining (Fig. 1B), three (33.3\%) exhibited 1+ staining, and four (44.4\%) exhibited 0 staining. The mean PFS was 5.7 and 2.5 years for primary tumours with 0 to $1+$ and $2+$ to $3+$ MGMT staining, respectively.

\section{Statistical analyses}

The tumours were dichotomised into low and high MGMT expression (0 to $1+$ and $2+$ to $3+\mathrm{im}$ munostaining, respectively). The statistical analyses of PFS and parameters were done by Kaplan-Meier analysis and compared using the log-rank test. The PFS was correlated with MGMT expression status (low vs. high expression) with statistical significance
( $p=0.0039$ ) (Fig. 3). No statistical significance was found between PFS and all the parameters, including gender, initial presentation of seizure, tumour size, tumour site, extent of surgery, and postoperative radiotherapy or chemotherapy.

\section{Discussion}

Ganglioglioma (GG) is a rare type of brain tumour. These tumours occur throughout the CNS system; however, the majority of GGs are localized in the temporal lobe (approximately $70 \%$ ) $[5,17,28]$. The typical GGs are benign tumours with indolent behaviour and correspond to WHO grade I. Only about $1 \%$ to $5 \%$ of all gangliogliomas exhibit anaplastic features in the glial component $[5,17]$ and are categorized as WHO grade III tumours. Gross total resection is recommended for GGs as the primary management [6]. Despite infrequent use of chemotherapy for low-grade GGs, it was still introduced to 

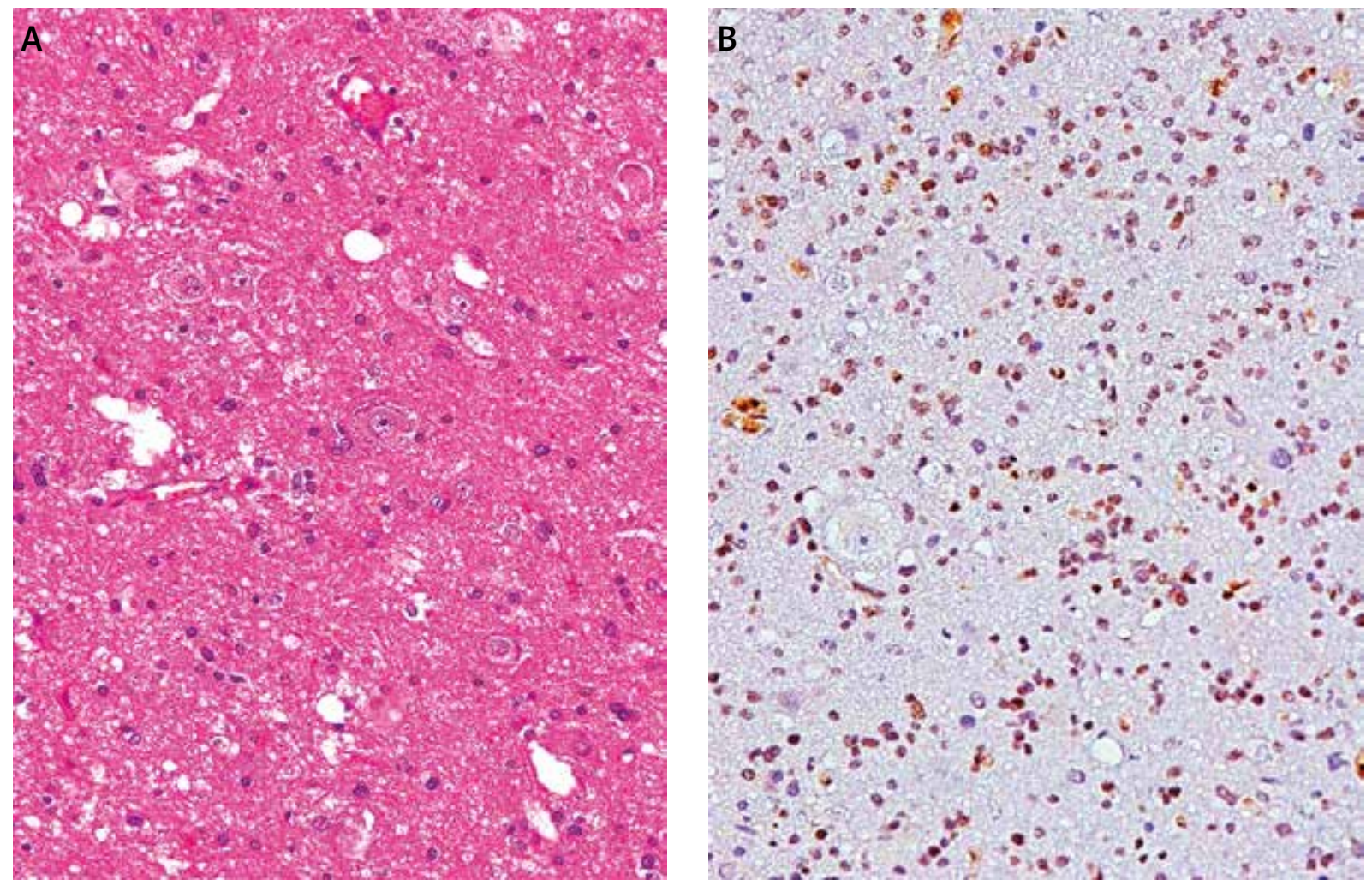

Fig. 1. Brain tumour of case 8 exhibited A) admixture of atypical neuronal cells and bland-looking glial cell component resembling fibrillary astrocytoma. Note the perimembranous aggregated Nissl substance of the neuron at the centre. B) The glial cells were 2+ positive for MGMT immunostains. The neurons were not stained. A) H\&E, ×200; B) MGMT immunostains, $\times 200$.

a subset of patients, especially those who had unresectable disease $[6,17]$.

The DNA-repair enzyme $0^{6}$-methylguanine-DNA methyltransferase (MGMT) is a key factor in resistance to alkylating agents $[15,19]$. Deficiency of the enzyme may increase the sensitivity of brain tumours to alkylating agents $[10,26]$. MGMT promoter methylation and epidermal growth factor receptor (EGFR) amplification may co-occur in one fifth $(19 \%)$ of patients with glioblastoma [1]. In the study of Esteller et al. [7], MGMT promoter methylation in glioma was associated with regression of the tumour and prolonged overall and disease-free survival. It was an independent prognostic factor for the patient with carmustine treatment in this study. In another study by Hegi et al. [8], not only was a survival benefit observed in patients treated with temozolomide and radiotherapy among patients whose tumour contained a methylated MGMT promoter, but also MGMT promoter methylation was an independent favourable prognostic factor irrespective of treatment. Theoretically, methylation of the MGMT promoter would affect MGMT protein expression. Some studies have demonstrated an association of MGMT expression by immunohistochemical study with the patient outcome [2,13]. However, others have shown no correlation between MGMT expression and patient survival [22,24].

In this study, we confirmed the indolent clinical behaviour of low-grade GG. Although two of nine cases (22.2\%) had recurrent tumours after gross total or subtotal resection in our case series, all patients survived the disease with a mean follow-up period of 6 years (range: 1.6 to 12.3 years). The status of MGMT protein expression demonstrated prognostic value for WHO grade I GGs. Tumours with more intensive MGMT protein expression $(2+\sim 3+$ immunostaining) tended to recur more frequently $(p<0.05)$, corresponding to the worse prognostic predictive value of intensive MGMT staining. In the current case series, patient 9 was the only one who underwent chemotherapy of temozolomide for postoperative adjuvant 

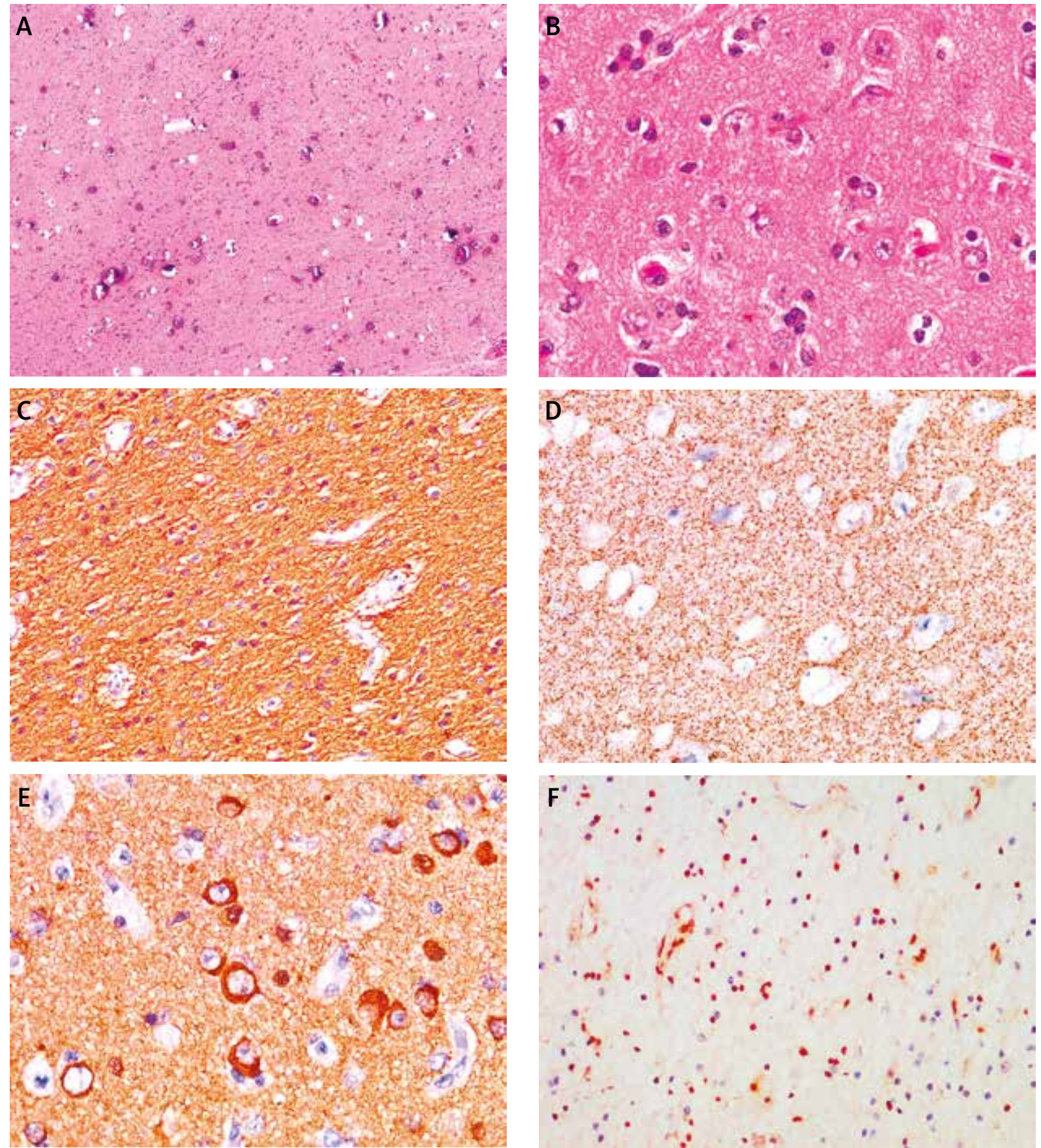

Fig. 2. Brain tumour of case 9. A) Dystrophic calcification. B) A biphasic differentiation pattern composed of glial and neuronal cellular elements. C) The glial component revealed intense staining for GFAP. The ganglion cells and their processes were immunoreactive to D) synaptophysin and E) NSE. F) Tumour cells revealed strong (3+) nuclear staining of MGMT. Note the internal positive control of endothelial cells. A) H\&E, $\times 40$;

B) $\mathrm{H} \&$ E, $\times 400$; C, F) GFAP, MGMT immunostains, $\times 200$; D, E) Synaptophysin, NSE immunostains, $\times 400$.

therapy in combination with radiotherapy at first diagnosis, as well as for recurrent disease. The intensive expression of MGMT demonstrated by immuno- histochemistry may explain the possible mechanism of unresponsiveness to temozolomide. To the best of our knowledge, this is the first report of descrip- 


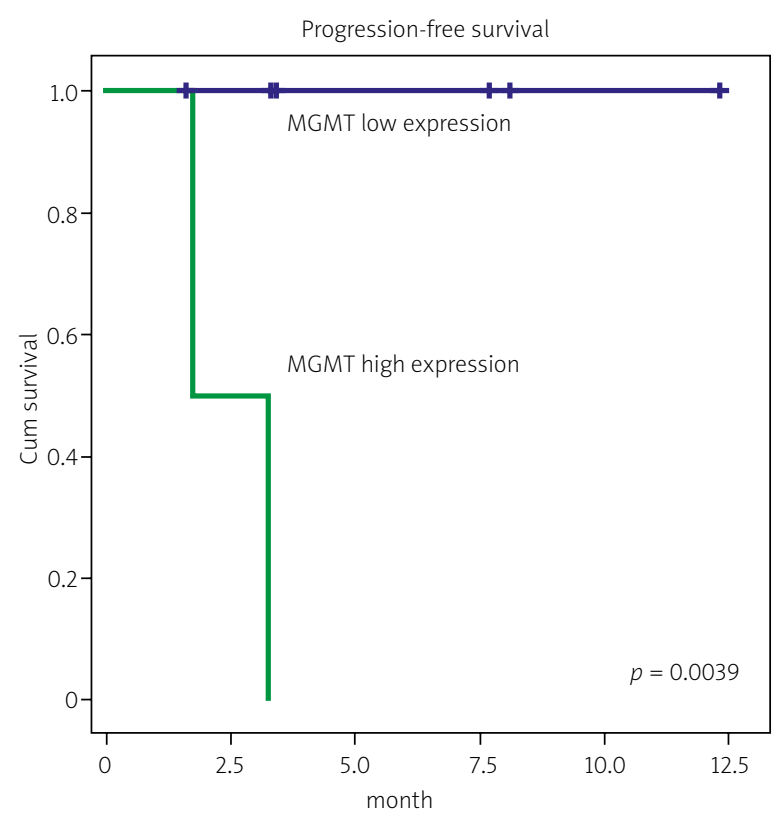

Fig. 3. Kaplan-Meier plots show that high MGMT expression (2+ 3+ immunostaining) conferred a significant prognostic impact on progression-free survival of patients with low-grade ganglioglioma $(p=0.0039)$.

tion of MGMT protein expression and MGMT protein status as potential prognostic factors in low-grade GGs. Due to the limited sample size of patients, further study is necessary to explore the association between MGMT expression and clinical outcome in GGs.

In conclusion, the current study demonstrated the indolent clinical behaviour of low-grade ganglioglioma. The intensive MGMT protein staining tended to be worse prognostic factors for patients with low-grade gangliogliomas $(p<0.05)$. We also supposed the unresponsiveness to temozolomide, a common alkylating agent used for malignant glioma, of case 9, was due to the strong expression of MGMT protein, which could remove alkyl groups to MGMT. For the candidate patients for treatment of temozolomide, we suggest that one should examine the MGMT expression status of the tumour before drug administration.

\section{Acknowledgements}

The authors are indebted to Dr. Chien-Feng Li for help and advice with statistical analyses. This work was supported by a grant (EDAHP102003) from E-DA Hospital, Kaohsiung, Taiwan.

\section{References}

1. Adamek D, Zazula M, Radwańska E, Grzywna E, Sińczak-Kuta A, Moskała M. Co-occurrence of MGMT gene promoter methylation and amplification of EGFR in glioblastoma. Wspolczesna Onkol 2011; 15: 362-366.

2. Anda T, Shabani HK, Tsunoda K, Tokunaga Y, Kaminogo M, Shibata S, Hayashi T, Iseki M. Relationship between expression of $\mathrm{O}^{6}$-methylguanine-DNA methyltransferase, glutathione-S-transferase pi in glioblastoma and the survival of the patients treated with nimustine hydrochloride: an immunohistochemical analysis. Neurol Res 2003; 25: 241-248.

3. Becker AJ, Löbach $M$, Klein $H$, Normann S, Nöthen $M M$, von Deimling A, Mizuguchi M, Elger CE, Schramm J, Wiestler OD, Blümcke I. Mutational analysis of TSC1 and TSC2 genes in gangliogliomas. Neuropathol Appl Neurobiol 2001; 27: 105-114.

4. Blümcke I, Beck H, Lie AA, Wiestler OD. Molecular neuropathology of human mesial temporal lobe epilepsy. Epilepsy Res 1999; 36: 205-223

5. Blumcke I, Wiestler OD. Gangliogliomas: an intriguing tumor entity associated with focal epilepsies. J Neuropathol Exp Neurol 2002; 61: 575-584.

6. Compton JJ, Laack NN, Eckel LJ, Schomas DA, Giannini C, Meyer FB. Long-term outcomes for low-grade intracranial ganglioglioma: 30-year experience from the Mayo Clinic. J Neurosurg 2012; 117: 825-830.

7. Esteller M, Garcia-Foncillas J, Andion E, Goodman SN, Hidalgo OF, Vanaclocha V, Baylin SB, Herman JG. Inactivation of the DNA-repair gene MGMT and the clinical response of gliomas to alkylating agents. N Engl J Med 2000; 343: 1350-1354.

8. Hegi ME, Diserens AC, Gorlia T, Hamou MF, de Tribolet N, Weller M, Kros JM, Hainfellner JA, Mason W, Mariani L, Bromberg JE, Hau P, Mirimanoff RO, Cairncross JG, Janzer RC, Stupp R. MGMT gene silencing and benefit from temozolomide in glioblastoma. N Engl J Med 2005; 352: 997-1003.

9. Hirose T, Scheithauer BW, Lopes MB, Gerber HA, Altermatt HJ, VandenBerg SR. Ganglioglioma: an ultrastructural and immunohistochemical study. Cancer 1997; 79: 989-1003.

10. Jaeckle KA, Eyre HJ, Townsend JJ, Schulman S, Knudson HM, Belanich M, Yarosh DB, Bearman SI, Giroux DJ, Schold SC. Correlation of tumor $\mathrm{O}^{6}$ methylguanine-DNA methyltransferase levels with survival of malignant astrocytoma patients treated with bis-chloroethylnitrosourea: a Southwest Oncology Group study. J Clin Oncol 1998; 16: 3310-3315.

11. Kalyan-Raman UP, Olivero WC. Ganglioglioma: a correlative clinicopathological and radiological study of ten surgically treated cases with follow-up. Neurosurgery 1987; 20: 428-433.

12. Lang FF, Epstein FJ, Ransohoff J, Allen JC, Wisoff J, Abbott IR, Miller DC. Central nervous system gangliogliomas. Part 2: Clinical outcome. J Neurosurg 1993; 79: 867-873.

13. Lechapt-Zalcman E, Levallet G, Dugue AE, Vital A, Diebold MD, Menei P, Colin P, Peruzzy P, Emery E, Bernaudin M, Chapon F, Guillamo JS. O(6) -methylguanine-DNA methyltransferase (MGMT) promoter methylation and low MGMT-encoded protein expression as prognostic markers in glioblastoma patients treated with biodegradable carmustine wafer implants after initial surgery followed by radiotherapy with concomitant and adjuvant temozolomide. Cancer 2012; 118: 4545-4554. 
14. Louis DN, Ohgaki H, Wiestler OD, Cavenee WK (eds.). WHO Classification of Tumours of the Central Nervous System. International Agency for Research on Cancer, Lyon 2007.

15. Ludlum DB. DNA alkylation by the haloethylnitrosoureas: nature of modifications produced and their enzymatic repair or removal. Mutat Res 1990; 233: 117-126.

16. Luyken C, Blumcke I, Fimmers R, Urbach H, Elger CE, Wiestler OD, Schramm J. The spectrum of long-term epilepsy-associated tumors: long-term seizure and tumor outcome and neurosurgical aspects. Epilepsia 2003; 44: 822-830.

17. Luyken C, Blumcke I, Fimmers R, Urbach H, Wiestler OD, Schramm J. Supratentorial gangliogliomas: histopathologic grading and tumor recurrence in 184 patients with a median follow-up of 8 years. Cancer 2004; 101: 146-155.

18. Morris HH, Matkovic Z, Estes ML, Prayson RA, Comair YG, Turnbull J, Najm I, Kotagal P, Wyllie E. Ganglioglioma and intractable epilepsy: clinical and neurophysiologic features and predictors of outcome after surgery. Epilepsia 1998; 39: 307-313.

19. Pegg AE, Dolan ME, Moschel RC. Structure, function, and inhibition of 06-alkylguanine-DNA alkyltransferase. Prog Nucleic Acid Res Mol Biol 1995; 51: 167-223.

20. Perkins O. Gangliogliomas. Arch Pathol Lab Med 1926; 2: 11-17.

21. Prayson RA, Khajavi K, Comair YG. Cortical architectural abnormalities and MIB1 immunoreactivity in gangliogliomas: a study of 60 patients with intracranial tumors. J Neuropathol Exp Neurol 1995; 54: 513-520.

22. Preusser M, Charles Janzer R, Felsberg J, Reifenberger G, Hamou MF, Diserens AC, Stupp R, Gorlia T, Marosi C, Heinzl H, Hainfellner JA, Hegi M. Anti-O ${ }^{6}$-methylguanine-methyltransferase (MGMT) immunohistochemistry in glioblastoma multiforme: observer variability and lack of association with patient survival impede its use as clinical biomarker. Brain Pathol 2008; 18: 520-532.

23. Qian XC, Brent TP. Methylation hot spots in the 5' flanking region denote silencing of the 06-methylguanine-DNA methyltransferase gene. Cancer Res 1997; 57: 3672-3677.

24. Rodriguez FJ, Thibodeau SN, Jenkins RB, Schowalter KV, Caron BL, O'Neill B P, James CD, Passe S, Slezak J, Giannini C. MGMT immunohistochemical expression and promoter methylation in human glioblastoma. Appl Immunohistochem Mol Morphol 2008; 16 59-65.

25. Selch MT, Goy BW, Lee SP, El-Sadin S, Kincaid P, Park SH, Withers HR. Gangliogliomas: experience with 34 patients and review of the literature. Am J Clin Oncol 1998; 21: 557-564.

26. Silber JR, Blank A, Bobola MS, Ghatan S, Kolstoe DD, Berger MS $\mathrm{O}^{6}$-methylguanine-DNA methyltransferase-deficient phenotype in human gliomas: frequency and time to tumor progression after alkylating agent-based chemotherapy. Clin Cancer Res 1999; 5: 807-814.

27. Watts GS, Pieper RO, Costello JF, Peng YM, Dalton WS, Futscher BW. Methylation of discrete regions of the $0^{6}$-methylguanine DNA methyltransferase (MGMT) CpG island is associated with heterochromatinization of the MGMT transcription start site and silencing of the gene. Mol Cell Biol 1997; 17: 5612-5619.

28. Wolf HK, Muller MB, Spanle M, Zentner J, Schramm J, Wiest ler OD. Ganglioglioma: a detailed histopathological and immunohistochemical analysis of 61 cases. Acta Neuropathol 1994; 88: 166-173.
29. Zhu JJ, Leon SP, Folkerth RD, Guo SZ, Wu JK, Black PM. Evidence for clonal origin of neoplastic neuronal and glial cells in gangliogliomas. Am J Pathol 1997; 151: 565-571. 